\title{
Does experimentally quieting traffic noise benefit people and birds?
}

\author{
$\underline{\text { Mitchell J. Levenhagen }}^{1}$, Zachary D. Miller ${ }^{2,3}$, Alissa R. Petrelli $^{4}, \underline{\text { Lauren A. Ferguson }}^{5}$, Yau-Huo (Jimmy) Shr $^{6}, \underline{\text { B. Derrick Taff }}^{7}$,

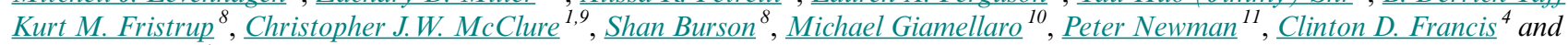 \\ Jesse R. Barber ${ }^{1}$
}

\begin{abstract}
Protected natural areas are not free from noise, especially noise generated by traffic within park boundaries. Natural soundscapes are important for maintaining community structure, providing positive visitor experiences, and increasing visitor support for management actions that reduce impacts on natural resources. To test experimental quieting as a strategy to increase both wildlife habitat quality and visitor experience, we enforced decreased speed limits and presented educational signage to reduce sound levels along a road system in an alternating, on-off block design within Grand Teton National Park, Wyoming, USA. We continuously recorded background sound levels while conducting bird space use assessments and visitor-intercept surveys along the experimental corridor. Our mitigation approach lowered sound levels during sign-present weeks, yet there was no relationship between bird space use near roadways and traffic noise, perhaps due to the increased duration of noise exposure created by lower speed limits. There was, however, a relationship between visitor perception of birdsong diversity and background sound level. Critically, visitors preferred soundscape mitigation strategies limiting personal access in exchange for better experiences in natural soundscapes.
\end{abstract}

Key Words: noise mitigation; protected areas; soundscape; speed limit reduction; traffic noise; visitor experience

\section{INTRODUCTION}

A $60 \%$ increase in global road length is anticipated by 2050 , or 25 million more kilometers of roadway than existed in 2010 (Dulac 2013). Roads have been instrumental in facilitating economic growth, yet their presence has many negative effects on ecological systems (Coffin 2007, Fahrig and Rytwinski 2009). In addition to decreasing habitat, roads fragment landscapes, dramatically increase land colonization, and lead to overexploitation of wildlife and other natural resources (Laurance et al. 2014, Ibisch et al. 2016). Traffic on roads comes with an additional suite of problems that are difficult to disentangle, including visual disturbance, large-scale deposition of chemical pollutants, direct mortality from collisions, and substantial noise pollution (Reijnen and Foppen 2006). However, the traffic noise effect zone can be higher than the footprint of other road effects (Madadi et al. 2017). Even protected areas are not free from traffic noise exposure; in fact, traffic is the largest source of anthropogenic noise in protected areas in the United States (Buxton et al. 2017).

Anthropogenic noise alters animal behaviors, distributions, stress responses, and fitness (Barber et al. 2010, Kight and Swaddle 2011, Francis and Barber 2013, Shannon et al. 2016). Elevated sound levels can mask acoustic information, lead to distraction, or induce informational masking (Dominoni et al. 2020). Small changes in sound levels matter and can result in negative responses in wildlife (Shannon et al. 2016). Studies focused on traffic noise have described increases in anti-predator behavior (Shannon et al. 2014), decreases in foraging success (Siemers and Schaub 2011, Bunkley and Barber 2015), disruption of mate-locating abilities (Bee and Swanson 2007, Gurule-Small and Tinghitella 2018), and reductions in reproductive success (Halfwerk et al. 2011, Kight et al. 2012, Kleist et al. 2018). Experimental, large-scale traffic noise playback research found that approximately one-third of a migratory songbird community avoided noise, with near complete avoidance in some species; further, those individuals that stayed during migratory stopover showed reduced body condition and reduced ability to gain weight, providing evidence that traffic noise alone is a source of habitat degradation (McClure et al. 2013, 2017, Ware et al. 2015).

Similar evidence indicates that human experiences in protected natural areas are negatively affected by noise (Pilcher et al. 2009, Benfield et al. 2018, Miller et al. 2018). Laboratory experiments found that noise from vehicles resulted in negative ratings of both landscape quality (Weinzimmer et al. 2014) and the soundscape (Marin et al. 2011). Although the National Park Service (NPS) manages soundscapes as a protected resource per NPS Director's Order \#47 (Peel 2000), national parks are not free from noise exposure (Barber et al. 2011, Lynch et al. 2011). A recent study found that noise pollution, primarily from traffic, doubled sound levels in nearly two-thirds of protected areas and resulted in a tenfold increase in approximately one-quarter of protected areas (Buxton et al. 2017). The pressures associated with traffic do not go unnoticed by park managers. In a system-wide national park unit questionnaire assessing road impacts on wildlife populations ( $N=106)$, more than one-half of the units responded that transportation within their park unit was at or above capacity, around one-quarter of units noted that traffic volumes were high or very high and expected to increase, and approximately onehalf of units expected effects to worsen over the subsequent five years (Ament et al. 2008). What remains unclear is the effectiveness of real-world traffic noise mitigation, and if successful, whether visitor-wildlife interactions are improved through soundscape mitigation.

${ }^{1}$ Boise State University, ${ }^{2}$ Institute of Outdoor Recreation and Tourism, Utah State University, ${ }^{3}$ Ecology Center, Utah State University, ${ }^{4}$ California Polytechnic State University, ${ }^{5}$ University of New Hampshire, ${ }^{6}$ Department of Agricultural Economics, National Taiwan University, ${ }^{7}$ Recreation, Park and Tourism Management, Penn State University, ${ }^{8}$ National Park Service, ${ }^{9}$ The Peregrine Fund, ${ }^{10}$ Oregon State University-Cascades, ${ }^{11}$ Penn State University 
We evaluated traffic speed reduction as a possible noise mitigation strategy through a manipulative study using reduced speed limits and educational signage in Grand Teton National Park, USA. While alternating between sign-absent and sign-present treatment conditions, we simultaneously conducted bird counts and visitorintercept surveys to test whether slower speeds, and associated quieter background sound levels, increased habitat use for birds and improved experiences for people. Previous research has called for investigations into reduced speed limits as a management strategy for improving roadside bird habitat (Parris and Schneider 2008, Ware et al. 2015, Francis et al. 2017). We predicted that speed limit reductions would decrease background sound levels, thus increasing bird space use near the roadway and increasing positive visitor experiences in the park. Positive experiences, as mediated through the soundscape, may increase visitor willingness to trade-off personal freedoms, such as speed limits, in return for opportunities to experience increased natural soundscapes and biodiversity.

\section{METHODS}

\section{Study site}

We conducted our study in 2016 in Grand Teton National Park, Wyoming, USA $\left(43^{\circ} 52^{\prime} \mathrm{N}, 110^{\circ} 23^{\prime} \mathrm{W}\right)$ during summer, which is peak season for breeding birds and visitor use. Traffic manipulations occurred along the John D. Rockefeller Jr. Parkway/US-191/US-287/US-89 highways in the east-central region of the park known as Oxbow Bend. During the 2016 NPS centennial, Grand Teton National Park received the second highest number of recreational visitors up to that year, with $>3.2$ million individuals visiting the park (National Park Service 2017).

\section{Traffic manipulations}

Traffic manipulations rotated in an on-off schedule during a total of 10 one-week blocks from 6 June to 14 August 2016. Because of project reconfiguration, week 3 through week 6 did not alternate and instead consisted of two sign-absent weeks (week 3 and week 4) followed by two sign-present weeks (week 5 and week 6). During treatment blocks we reduced speed limits from 72 to $40 \mathrm{~km} / \mathrm{h}$ and placed roadside educational and enforcement signage both northbound and southbound along the $\sim 2.5 \mathrm{~km}$ experimental road corridor (Fig. 1; Fig. S1 in Appendix 1). We placed two decibel meter signs within the corridor facing each direction. The signs used a wireless sound level reader placed in the road shoulder leading to the display that showed the sound level of the passing vehicle on a green-yellow-red scale, where green $=$ low, yellow $=$ intermediate, and red $=$ high )

We collected vehicle speed data within the road corridor using a PicoCount 2500 (https://www.vehiclecounts.com) automatic traffic counter and classifier to calculate the average traffic count and average traffic speed. Two pneumatic tubes were stretched over the highway approximately $91 \mathrm{~cm}$ apart and secured with rope and spikes in the road shoulder. Using the program TrafficViewer Pro (https://www.vehiclecounts.com), we summarized traffic counter data into five speed ranges. Speed data were nonnormally distributed and analyzed using a Kruskal-Wallis test with the "kruskal.test" function in R (R Core Team 2016) for each treatment condition. The traffic counter was operational from 8 June through 21 June, 28 June through 30 June, and 12 July through 7 August 2016.
Fig. 1. Survey locations and site layout along experimental road corridor.

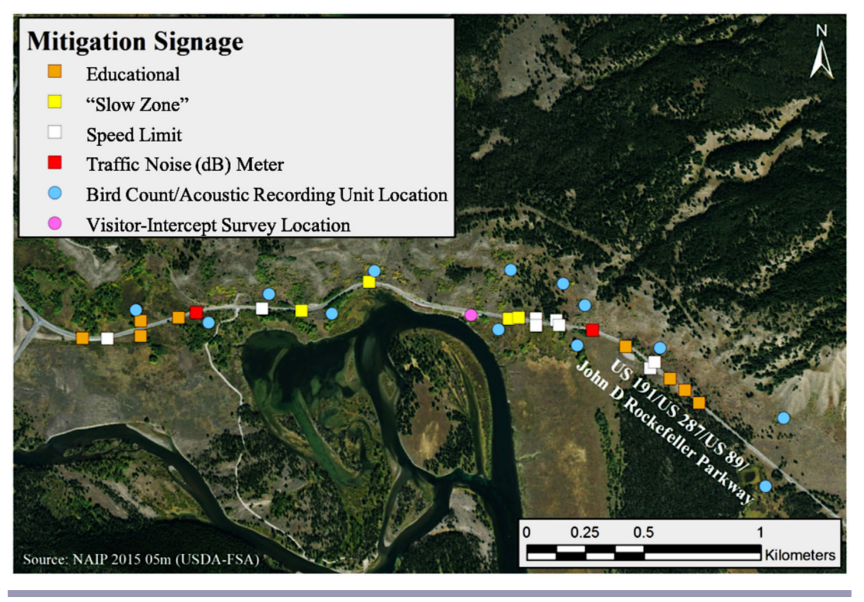

\section{Acoustic measurements}

To assess background sound levels between treatment blocks during the 70-day study, we continuously measured hourly L50 levels (sound level met or exceeded for $50 \%$ of the measurement time) along the road corridor using 13 acoustic recording units (ARUs; R-05s, Roland, California, USA) located between $~ 50$ and $200 \mathrm{~m}$ from the roadway (Fig. 1). ARUs were suspended within a camouflaged fabric windscreen and mounted to vegetative structures approximately 1 to $1.5 \mathrm{~m}$ off the ground. Units were set to record MP3 files using a $44.1 \mathrm{kHz}$ sampling rate and 128 kilobits-per-second recording mode. ARUs were powered by lithium iron phosphate (LiFePO4) rechargeable batteries (https://www.batteryspace.com) housed within a waterproof plastic container, and power supply cords were encased within rubber hosing to protect them from damaged caused by small mammals.

We converted a total of 19,386 h of acoustic recordings using custom programs AUDIO2NVSPL and Acoustic Monitoring Toolbox (Damon Joyce, programmer, NPS) into hourly L50 sound pressure levels. Data from two ARUs were excluded from the analysis because the stations fell outside the experimental road corridor. Data from 10 July 2016 were excluded from the analysis because of elevated ambient noise because of heavy precipitation. From these hourly values, we calculated the daily average for each site using the period between $1 \mathrm{~h}$ prior to and after ( 0600 to 1300) point count start and end times, resulting in a total of $4728 \mathrm{~h}$ measured. We compared daily average L50 A-weighted decibels $(\mathrm{dB}[\mathrm{A}])$, or decibels adjusted based on human hearing), using the Wilcoxon rank-sum test between sign-absent and sign-present treatment blocks across all ARU sites. Missing data for three dates were estimated for use in bird survey analysis by averaging sound pressure levels from the two closest dates with available data.

\section{Bird surveys}

We surveyed birds 20 times at each of 10 sites co-located with ARUs throughout the 10 -wk period. We added one site during the study and used the final six weeks of survey data (12 surveys) from this site in subsequent analyses. Our single observer 
Table 1. Comparison of marginal utility coefficients between sign-absent and sign-present treatment groups.

\begin{tabular}{|c|c|c|c|}
\hline Attribute & $\begin{array}{l}\text { Coefficient } \\
\text { difference }\end{array}$ & $\begin{array}{l}\text { Asymptomatic } t- \\
\text { ratio }^{\dagger}\end{array}$ & $P$ \\
\hline \multicolumn{4}{|l|}{ Information and enforcement management actions } \\
\hline 1. No signs are posted along the road about natural quiet & --- & --- & --- \\
\hline 2. Signs are posted along the road educating visitors about natural quiet & 0.518 & 3.542 & $<0.001$ \\
\hline $\begin{array}{l}\text { 3. Signs are posted along the road educating visitors about natural quiet and asking visitors to limit } \\
\text { noise }\end{array}$ & 0.310 & 1.676 & 0.009 \\
\hline $\begin{array}{l}\text { 4. Signs are posted along the road educating visitors about natural quiet and asking visitors to limit } \\
\text { noise, and rangers are stationed along the road to limit visitor-caused noise }\end{array}$ & 0.407 & 2.277 & 0.002 \\
\hline $\begin{array}{l}\text { 5. Signs are posted along the road educating visitors about natural quiet and asking visitors to limit } \\
\text { noise, and rangers are enforcing visitors to limit noise along the road }\end{array}$ & 0.254 & 1.616 & 0.107 \\
\hline \multicolumn{4}{|l|}{ Speed limits } \\
\hline 1. You can drive $72 \mathrm{~km} / \mathrm{h}(45 \mathrm{mi} / \mathrm{h})$ on park roads near important wildlife habitat & --- & --- & --- \\
\hline 2. You can drive $56 \mathrm{~km} / \mathrm{h}(35 \mathrm{mi} / \mathrm{h})$ on park roads near important wildlife habitat & 0.512 & 5.253 & $<0.001$ \\
\hline 3. You can drive $40 \mathrm{~km} / \mathrm{h}(25 \mathrm{mi} / \mathrm{h})$ on park roads near important wildlife habitat & 0.140 & 0.733 & 0.464 \\
\hline 4. You can drive $24 \mathrm{~km} / \mathrm{h}(15 \mathrm{mi} / \mathrm{h})$ on park roads near important wildlife habitat & --- & --- & --- \\
\hline
\end{tabular}

completed twice-weekly bird count surveys between 0700 and 1200 based on a modified protocol developed by Rocky Mountain Bird Observatory (Hanni et al. 2009). Because detection of birds varies by both date and time, we randomized point count location order. Surveys lasted for $5 \mathrm{~min}$ each, with our observer recording both the total number of birds observed and method of observation (e.g., visual, song) for each minute of the survey. Our observer used a laser rangefinder (TruPulse 360R, Laser Technology, Inc., Colorado) to record the distance from bird count center for each observation. We truncated our bird count analysis to observations within $50 \mathrm{~m}$ to allow for a fine-scale understanding of space use within a bird's territory.

After testing for the effect of treatment on bird count detectability (Appendix 1), we analyzed bird counts with package "lme4" (Bates et al. 2015) in R using a generalized linear mixed-effects model (GLMM) with total bird count by site as the response variable, daily-averaged L50 ( $\mathrm{dB}[\mathrm{A}])$ and Julian date as fixed effects, and site as a random effect. Fixed effects were scaled for interpretation and to allow individual models to converge. Julian date was included because of its relationship with both background sound levels (our systematic on-off block design) and bird count (e.g., lower counts in the latter parts of the breeding season). Conditional $R^{2}$ values $\left(R_{\text {GLMM[C }}^{2}\right.$ ), i.e., variance explained by both fixed and random effects, were calculated using package "MuMIn" (Bartoń 2016) and function "r. squaredGLMM" in R. In addition to a GLMM incorporating total bird count for all species per site, individual GLMMs were built for each species with $>100$ overall observations.

\section{Visitor behavior and experience}

Trained university researchers used intercept survey techniques to sample Grand Teton National Park visitors systematically between 19 July and 14 August 2016. We stratified data collection to represent weekends, weekdays, time of day (all times during daylight hours), and sign-absent and sign-present periods. To avoid a self-selection bias when intercepting a group, the person with the most recent birthday was asked to participate in completing the survey. Participants received a laminated copy of the survey, and responses were recorded in situ by survey administrators on an electronic tablet device using Qualtrics survey software to securely store data.
Intercept surveys assessed visitor trade-offs among a range of potential management actions related to soundscape management in Grand Teton National Park. The survey included nine different paired scenarios, of which participants were asked to make a discrete choice between the two. These methods reflect the complex nature of park management in that they force respondents to make trade-offs among conflict desires, including access and ecological protection (Newman et al. 2005). We developed two versions of the survey to increase the number of scenarios tested. Management actions included both direct (e.g., enforcement, restrictions) and indirect (e.g., education, information) components for two different attributes: information to enforcement and speed limits (Table 1; Manning 2011). Information to enforcement contained five different levels of sign use and enforcement, and the speed limit attribute focused on driving speed near important wildlife habitat (Table 1). Sound preference was measured as an attribute and used to standardize the statistical model across the two groups (signs present and signs absent) to allow for comparison.

The survey included a stated choice experiment (Holmes et al. 2017) in which visitor responses were combined and analyzed to produce estimates, or utility scores, for the level of preference for each of the attributes. Higher utility scores indicate more preference for an attribute, and lower ones indicate less of a preference. This approach has been used in a wide variety of environmental and natural resource management settings, including many in the area of outdoor recreation and park management to explore visitor preferences (Lawson and Manning 2002, 2003, Newman et al. 2005, Cahill et al. 2008).

We used random parameter (mixed) logit modeling to analyze the stated choice data and estimate the utility scores representing the level of preference for each of the attributes. To analyze our stated choice model, we dummy coded the attributes of information to enforcement and closures. We used the management action "no signs are posted along the trail about natural quiet" and "trails are open during operating hours" as the baseline condition. The estimates of each attribute therefore indicate the marginal changes in utility score from the corresponding baseline condition. To compare utility scores between sign-absent and sign-present groups we used $t$-tests. 
In our intercept surveys, we also asked visitors about the importance of 18 different reasons and motivations for park travel. We created a sound motivation index based on a subset of the reasons and motivations that pertained to the importance of sound and sound experience (e.g., to enjoy the natural quiet and sounds of nature, get away from the noise at home, enjoy the peace and quiet, and hear the sounds of nature). Individuals with a higher sound motivation index score were more motivated to experience natural sounds during their park visit.

In addition, we assigned a noise sensitivity index score to respondents based on a five-question noise sensitivity survey. The survey asked respondents whether they agree or disagree with whether they are sensitive to noise, have difficulty relaxing in a noisy place, get mad at people who make noise and prevent them from falling asleep or getting work done, get annoyed with noisy neighbors, and get used to noises without much difficulty. Individuals with a higher noise sensitivity score had greater sensitivity to noise and noisy places.

Visitor-intercept surveys also asked respondents to rate bird chorus diversity based on their listening experience that day, as well as to rank soundscape pleasantness on a six-point categorical scale from very unpleasant to very pleasant. Using the "polr" function in R package "MASS" (Venables and Ripley 2002), we performed proportional odds logistic regressions to assess visitor perception of birdsong diversity and visitors' pleasantness ranking of the soundscape. We used the number of species counted during bird surveys and the hourly sound level for the hour in which the survey was administered as predictors in each respective model. The ARU closest to the turnout location where surveys were administered was used for the hourly sound level measurement. We also used the polr function to assess the relationships between hourly sound level, sound motivation, noise sensitivity, and visitor ratings of soundscape pleasantness. Given the novel nature of this research, we focused on linear relationships in the bird chorus diversity and soundscape pleasantness analyses.

\section{RESULTS}

\section{Acoustic environment and road manipulations}

Sound levels (L50 dB[A]) along the road were higher during signabsent treatment blocks (Wilcoxon rank-sum test, $N=687, W=$ $74,404, P<0.001)$. Sign-absent sound levels averaged $46.9 \pm 0.10$ $\mathrm{dB}(\mathrm{A})$ (mean \pm standard error [SE]), whereas sign-present levels averaged $45.4 \pm 0.10 \mathrm{~dB}(\mathrm{~A})$, a $1.5 \mathrm{~dB}$ reduction. This decrease in background sound levels between sign-absent and sign-present blocks is equivalent to $29 \%$ increase of an individual's listening area, the distance at which an individual is able to detect acoustic signals (Barber et al. 2010).

Our traffic counter quantified 114,819 northbound and southbound vehicles during the sign-absent treatment blocks and 109,090 vehicles during sign-present treatment blocks. The majority of vehicles were categorized as traveling 72 to $79 \mathrm{~km} / \mathrm{h}$ $(N=46,199)$ during sign-absent blocks and 56 to $63 \mathrm{~km} / \mathrm{h}(N=$ 21,564) during sign-present blocks (Table S1 in Appendix 1). After grouping events into four speed limit bins, we found a relationship between driving speed and treatment for the 8 to $38 \mathrm{~km} / \mathrm{h}$ (Kruskal-Wallis chi-squared $=51.62, N=6129, \mathrm{df}=1, P<0.001$ ), 40 to $79 \mathrm{~km} / \mathrm{h}$ (Kruskal-Wallis chi-squared $=6.90, N=172,605$, df $=1, P=0.009$ ), and 80 to $119 \mathrm{~km} / \mathrm{h}$ (Kruskal-Wallis chisquared $=37.73, N=45,044, \mathrm{df}=1, P<0.001)$ speed limit bins (Table S2 in Appendix 1), with vehicles driving slower when mitigation signage was present. There was no relationship between driving speed and treatment for the $\geq 120 \mathrm{~km} / \mathrm{h}$ speed limit bin (Kruskal-Wallis chi-squared $=0.17, N=131$, df $=1, P$ $=0.68$; Table S2 in Appendix 1).

\section{Bird observations}

We recorded 1402 observations of 43 bird species within $50 \mathrm{~m}$ of the center of our bird count locations (Table S3 in Appendix 1). Of these observations, eight species were recorded $\geq 50$ times, representing $68 \%$ of all observations. In our model incorporating bird count for all species, there was no relationship between bird count and sound level $(N=212$, standard deviation $[\mathrm{SD}]=3.38$, scaled $\beta=-0.05 \pm 0.06, P=0.32,95 \%$ confidence interval $[\mathrm{CI}]$ : -0.16 to 0.05$)$. However, there was a significant negative relationship between bird count and Julian date $(N=212, \mathrm{SD}=$ 20.22, scaled $\beta=-0.21 \pm 0.03, P=<0.001,95 \% \mathrm{CI}:-0.27$ to -0.16; Table S4 in Appendix 1). In the individual models for each of the four species with $>100$ observations (Setophaga petechia, Yellow Warbler; Zonotrichia leucophrys, White-crowned Sparrow; Empidonax oberholseri, Dusky Flycatcher; Vireo gilvus, Warbling Vireo), there was no relationship between species count and background sound levels (Table S4 in Appendix 1). However, three of four models found a negative relationship between bird count and Julian date (Yellow Warbler: $N=212$, scaled $\beta=-0.32 \pm 0.06$, $P<0.001,95 \%$ CI: -0.44 to -0.20 ; White-crowned Sparrow: $N$ $=212$, scaled $\beta=-0.07 \pm 0.08, P=0.40,95 \% \mathrm{CI}:-0.23$ to 0.09 ; Dusky Flycatcher: $N=212$, scaled $\beta=-0.21 \pm 0.10, P=0.03$, 95\% CI: -0.40 to -0.02 ; Warbling Vireo: $N=212$, scaled $\beta=$ $-0.45 \pm 0.10, P<0.001,95 \%$ CI: -0.65 to -0.26 ).

\section{Visitor experience of bird chorus diversity and soundscape pleasantness}

A total of 471 individuals agreed to complete the survey, resulting in an $82 \%$ response rate from the sampling effort. Visitor rating of bird chorus diversity showed a negative relationship with sound level $(N=468, \beta=-0.11 \pm 0.03, P<0.001,95 \% \mathrm{CI}:-0.18$ to -0.05 ; Fig. $2 \mathrm{~A}$ ). Sound level was not a predictor of visitor ranking of soundscape pleasantness $(N=460, \beta=0.02 \pm 0.03, P=0.38$, $95 \%$ CI: -0.03 to 0.08$)$. However, visitor noise sensitivity and motivation to experience sounds in the park were predictors of their rankings of soundscape pleasantness, with increasing noise sensitivity decreasing pleasantness scores $(N=460, \beta=-0.34$ $\pm 0.09, P<0.001,95 \%$ CI: -0.52 to -0.17 ; Fig. $2 \mathrm{~B})$ and increasing motivation to experience sounds increasing pleasantness scores $(N=460, \beta=0.25 \pm 0.09, P<0.01,95 \%$ CI: 0.08 to 0.43 ; Fig. $2 B)$.

\section{Visitor preferences for soundscape management strategies}

In the random parameter logit model, the management actions "No signs are posted along the road about natural quiet," "You can drive $72 \mathrm{~km} / \mathrm{h}$ on park roads near important wildlife habitat," and "Park roads near important wildlife habitat are open $24 \mathrm{~h}$ " were used as the respective baseline condition, and therefore, the associated coefficients were normalized to zero (Table 2). Overwhelmingly, visitors supported at least some form of visitorcaused noise management through sign use, as indicated by the significantly positive utility scores for all four management actions with signs posted (Table 2). Of all management options involving signage, visitors' strongest preference was for signs that 
educated visitors about natural quiet, asked visitors to limit their noise, and had rangers stationed along the road to limit visitor noise. Collectively, visitors had the highest utility scores for management options "Signs are posted along the road educating visitors about natural quiet and asking visitors to limit noise" and "Signs are posted along the road educating visitors about natural quiet and asking visitors to limit noise, and rangers are stationed along the trail to limit visitor-caused noise." Both of these options promote an appreciation of natural quiet and move to limit visitor caused noise (indirectly through signs and rangers). The significant SDs of the attribute coefficients (Table 2) indicate that although, on average, respondents support management options for limiting noise, there is considerable preference heterogeneity among respondents.

Fig. 2. Background sound levels and visitor traits affect soundscape experiences. (a.) Probability of visitor-reported bird chorus diversity ratings in response to sound level (L50 dB(A)). (b.) Probability of visitor-reported soundscape pleasantness ratings in relation to sound motivation and noise sensitivity indexes.
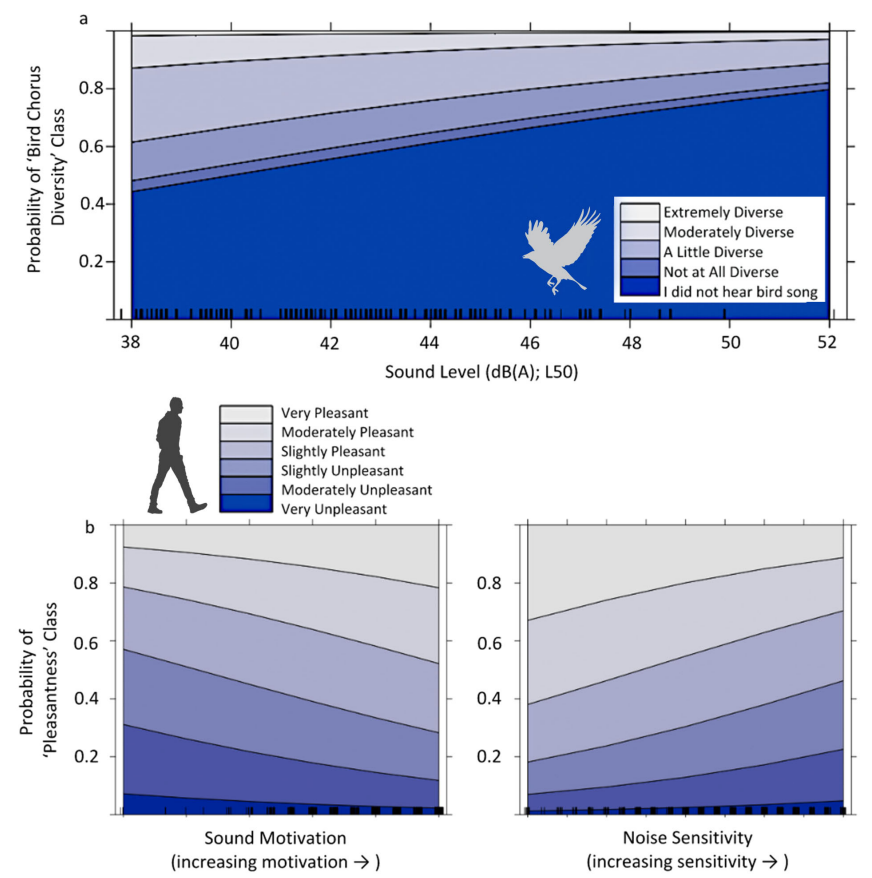

On average, respondents supported reducing the speed limit from $72 \mathrm{~km} / \mathrm{h}$ to $56 \mathrm{~km} / \mathrm{h}$ or $40 \mathrm{~km} / \mathrm{h}$, as evidenced by the significant coefficients for the $56 \mathrm{~km} / \mathrm{h}$ and $40 \mathrm{~km} / \mathrm{h}$ management levels (Table 2). The insignificant coefficients of road closure indicated that respondents are not against management actions limiting access for protecting breeding bird chorus, either after dawn or after dawn and evening. The significant SDs of the associated coefficients indicated that the respondents' opinions vary (Table 2).

These patterns were consistent across both sign-absent and signpresent periods. The presence of mitigation signage affected visitor preference for mitigations action. To test the differences between the two coefficients across the control and treatment, we estimated the individual parameters conditional on the choices made for the nine choice scenarios for all respondents (Revelt and Train 2000) and performed $t$-tests (Table 1). Three of four utility scores, quantitative proxies of visitor management action preferences for level of sign use (information to enforcement; Table 1), showed a relationship with treatment condition $(N=2$, $P<0.01 ; N=1, P<0.001 ;$ Fig. 3$)$. In other words, when mitigation signage was present, visitors more strongly preferred three of four sign management actions than when mitigation signage was absent. Only one of three utility scores for speed limit levels ("You can drive $56 \mathrm{~km} / \mathrm{h}$ on park roads near important wildlife habitat"; Table 1) showed a relationship with treatment condition $(P<$ 0.001 ; Fig. 4). When signs were present, visitors more strongly preferred reducing speed limits from $72 \mathrm{~km} / \mathrm{h}$ to $56 \mathrm{~km} / \mathrm{h}$ compared to respondents in the sign-absent treatment condition. Neither of the two management levels for road closures were supported by visitors $(P>0.05$; Table 2$)$.

Fig. 3. Comparison of marginal utility coefficients for information and enforcement management actions. Significant differences between signs present and signs absent conditions are indicated by asterisks, where $* \mathrm{p}<0.05,{ }^{*} \mathrm{p}<0.01, * * * \mathrm{p}<$ 0.001

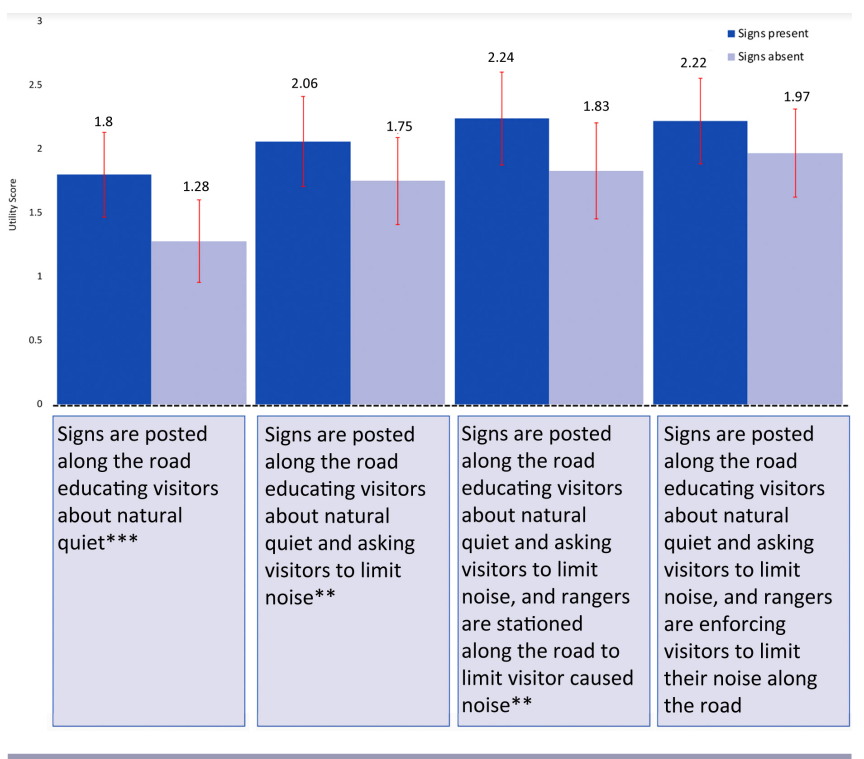

\section{DISCUSSION}

Our experimental quieting via speed limit reductions and educational signage along the Oxbow Bend road corridor in Grand Teton National Park decreased background sound levels, thereby increasing opportunities for visitor to hear birds. When signs were present, people more strongly preferred management options aimed at managing soundscapes and lowered their noise footprint through compliance with speed limit reductions. However, there was no relationship between measured sound levels and bird space use near the road corridor. Additionally, visitor-reported soundscape pleasantness did not show a relationship with background sound levels measured at the time 
Table 2. Results from the stated choice model for visitor preferences for soundscape management for sign-absent and sign-present conditions. All parameters are assumed to be normally distributed, while correlations are allowed only within levels of each attribute. The model was normalized by preference for bird song.

\begin{tabular}{|c|c|c|c|c|c|c|}
\hline \multirow[b]{2}{*}{ Attribute } & \multicolumn{3}{|c|}{ Signs present (treatment) } & \multicolumn{3}{|c|}{ Signs absent (control) } \\
\hline & Coefficient & $\mathrm{SE}^{\dagger}$ & $P$ & Coefficient & $\mathrm{SE}^{\dagger}$ & $P$ \\
\hline \multicolumn{7}{|l|}{ Information and enforcement management actions } \\
\hline 1. No signs are posted along the road about natural quiet & Baseline condition & -- & -- & Baseline condition & -- & -- \\
\hline $\begin{array}{l}\text { 2. Signs are posted along the road educating visitors about } \\
\text { natural quiet }\end{array}$ & 1.796 & 0.332 & $<0.001$ & 1.278 & 0.323 & $<0.001$ \\
\hline $\begin{array}{l}\text { 3. Signs are posted along the road educating visitors about } \\
\text { natural quiet and asking visitors to limit noise }\end{array}$ & 2.063 & 0.353 & $<0.001$ & 1.753 & 0.341 & $<0.001$ \\
\hline $\begin{array}{l}\text { 4. Signs are posted along the road educating visitors about } \\
\text { natural quiet and asking visitors to limit noise, and } \\
\text { rangers are stationed along the road to limit visitor- } \\
\text { caused noise }\end{array}$ & 2.238 & 0.364 & $<0.001$ & 1.831 & 0.376 & $<0.001$ \\
\hline $\begin{array}{l}\text { 5. Signs are posted along the road educating visitors about } \\
\text { natural quiet and asking visitors to limit noise, and } \\
\text { rangers are enforcing visitors to limit their noise along } \\
\text { the road }\end{array}$ & 2.224 & 0.335 & $<0.001$ & 1.970 & 0.345 & $<0.001$ \\
\hline \multicolumn{7}{|l|}{ Speed limits } \\
\hline $\begin{array}{l}\text { 1. You can drive } 72 \mathrm{~km} / \mathrm{h}(45 \mathrm{mi} / \mathrm{h}) \text { on park roads near } \\
\text { important wildlife habitat }\end{array}$ & Baseline condition & -- & -- & Baseline condition & -- & -- \\
\hline $\begin{array}{l}\text { 2. You can drive } 56 \mathrm{~km} / \mathrm{h}(35 \mathrm{mi} / \mathrm{h}) \text { on park roads near } \\
\text { important wildlife habitat }\end{array}$ & 1.431 & 0.264 & $<0.001$ & 0.919 & 0.245 & $<0.001$ \\
\hline $\begin{array}{l}\text { 3. You can drive } 40 \mathrm{~km} / \mathrm{h}(25 \mathrm{mi} / \mathrm{h}) \text { on park roads near } \\
\text { important wildlife habitat }\end{array}$ & 1.169 & 0.282 & $<0.001$ & 1.029 & 0.302 & $<0.001$ \\
\hline $\begin{array}{l}\text { 4. You can drive } 24 \mathrm{~km} / \mathrm{h}(15 \mathrm{mi} / \mathrm{h}) \text { on park roads near } \\
\text { important wildlife habitat }\end{array}$ & 0.170 & 0.341 & 0.618 & 0.039 & 0.351 & 0.911 \\
\hline \multicolumn{7}{|l|}{ Closures } \\
\hline 1. Park roads near important wildlife habitat are open $24 \mathrm{~h}$ & Baseline condition & -- & -- & Baseline condition & -- & -- \\
\hline $\begin{array}{l}\text { 2. Park roads near important wildlife habitat are closed } 1 \mathrm{~h} \\
\text { after dawn for the morning breeding bird chorus }\end{array}$ & 0.126 & 0.174 & 0.470 & -0.156 & 0.196 & 0.425 \\
\hline $\begin{array}{l}\text { 3. Park roads near important wildlife habitat are closed for } \\
1 \mathrm{~h} \text { after dawn and } 1 \mathrm{~h} \text { in the evening for the breeding } \\
\text { bird chorus }\end{array}$ & 0.251 & 0.216 & 0.246 & -0.073 & 0.224 & 0.744 \\
\hline Number of choice questions & 3752 & & & & & \\
\hline Number of parameters & 61 & & & & & \\
\hline Log-likelihood ratio & -1999.15 & & & & & \\
\hline Pseudo $R^{2}$ & 0.2175 & & & & & \\
\hline
\end{tabular}

Fig. 4. Comparison of marginal utility coefficients for speed limit management strategies to reduce roadside background sounds levels. Significant differences between signs-present and signs-absent conditions are indicated by asterisks, where $* * * P$ $<0.001 .35 \mathrm{MPH}=56 \mathrm{~km} / \mathrm{h}, 25 \mathrm{MPH}=40 \mathrm{~km} / \mathrm{h}$, and $15 \mathrm{MPH}$ $=24 \mathrm{~km} / \mathrm{h}$.

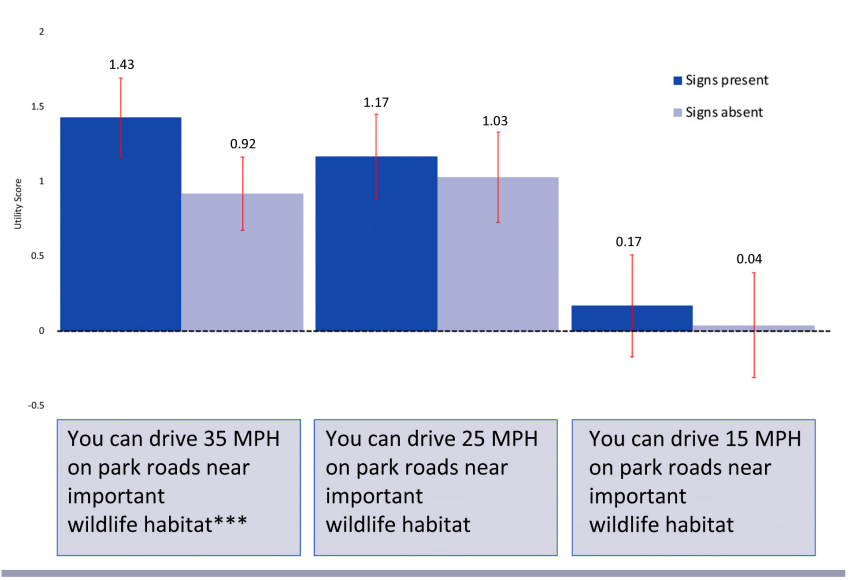

surveys were administered. The sound level relief we measured $(1.5 \mathrm{~dB}[\mathrm{~A}])$ was at a level greater than the amount at which humans are able to distinguish a noticeable difference $(1 \mathrm{~dB}$ over a range of sound levels; National Research Council 2004). There was a positive relationship between soundscape pleasantness and visitor motivation to hear sounds and a negative relationship between soundscape pleasantness and visitor noise sensitivity. We found a positive feedback loop, whereby mitigation actions decreased sound levels, increased access to natural sounds, and resulted in stronger visitor support for soundscape mitigation strategies and quieter soundscapes.

Although ratings of soundscape pleasantness did not change, visitors perceived greater bird diversity when mitigation signage was present and sound levels were lower, which is an important finding relating to visitor experiences in protected natural areas. Opportunities to experience natural sounds such as birdsong are ranked as key motivations and reasons for protecting these spaces (Marin et al. 2011). Birds were present in the landscape for people to hear, and when mitigation signage was present and it was quieter, people perceived greater biodiversity. Increased perceived biodiversity is linked to a greater valuation of ecosystem services (Belaire et al. 2015). Under normal speed limits, background 
sound levels may mask these natural sounds from human listeners, ultimately resulting in lost listening opportunities. Visitor understanding of conservation actions paired with the realized benefits of such actions are crucial for the willingness for and success of mitigation strategies (Ballantyne et al. 2009). This understanding and realization is key in instilling a sense of conservation action and support in visitors of protected natural areas (Ballantyne et al. 2009).

Unsurprisingly, bird counts decreased as the breeding season progressed. Despite increases in biodiversity perception, actual bird use of space near the roadway remained unchanged in relation to sound level. The relatively small change in sound level we induced $(1.5 \mathrm{~dB}[\mathrm{~A}])$, in combination with the background intensity of the acoustic environment ( $\sim 5 \mathrm{~dB}[\mathrm{~A}])$, likely limited our ability to detect a response in birds, even if present. Interestingly, although not significant, the fixed effect of sound level on bird abundance was negative in all models (though the effect for sound level was $<0.1$ for each model).

One hypothesis for why bird abundance did not change is that perhaps productive breeding habitat (e.g., riparian areas with substantial willow cover) in close proximity to the road corridor outweighed the potential negative effects of remaining in noiseexposed areas. Another possible reason may be due to changes in temporal soundscape characteristics caused by speed limit reductions. Experimental speed limit reductions created longer noise exposure from vehicle pass by events, for any given location on the landscape. Instead of vehicles passing at faster speeds and thereby creating a shorter duration of noise exposure, reductions in speed limit resulted in a longer period of noise exposure. If this exposure level was still above the threshold that would result in increased use of the area by birds, no change would be expected. It seems that slower driving speeds might not be the ideal method for noise mitigation, perhaps due to this extended noise exposure of individual pass by events. Additionally, birds may have avoided masking by traffic noise by using gaps in background noise to more effectively transmit and receive acoustic signals, a strategy found in multiple species (Gentry et al. 2017, Lee et al. 2017, Proppe and Finch 2017).

Slower speed limits and thus reductions in sound level did not impact visitor rating of soundscape pleasantness. Instead, noise sensitivity had the strongest effect for predicting ratings of soundscape pleasantness, matching previous laboratory research (Guillén and López Barrio 2007, Benfield et al. 2014). Ratings of soundscape pleasantness may instead be related to visitor expectations for the roadside parking area where surveys were administered. Previous laboratory and field research has found that the majority of participants in these types of studies had predetermined expectations of sounds present within spaces, sound controllability, and the compatibility of behaviors to the spaces (Davies et al. 2009, Bruce and Davies 2014). Visitors likely expected to hear traffic noise and understood their lack of control in avoiding noise along the roadside.

Although our results demonstrate that signs are an effective noise mitigation strategy with significant positive impacts on visitor soundscape experience, we note that our study had limitations. One such limitation is that we cannot rule out impacts from other components of road effects such as visual disturbance, chemical pollution, direct collisions, or downstream consequences of stress.
Importantly, because the reduction in sound level we achieved was relatively small, we may not have been able to detect changes in bird behavior if they were indeed present. As mentioned, our study occurred during the breeding season when birds had already established territories and were limited to bounded areas; thus, we focused on individual space use within set territories, which was undoubtedly less labile than in other life cycle stages. For example, it would be interesting to investigate the effects of experimental quieting during migration (Ware et al. 2015). Other traffic noise reduction strategies such as quiet pavement or crepuscular road closures are additional promising avenues of research.

\section{CONCLUSION}

Soundscape management can be used as a conservation tool to enhance visitor perception and appreciation for nature and protected areas. Our mitigation actions increased visitor conservation support through reduced anthropogenic noise exposure and improved access to natural sounds and biodiversity. Speed limit reductions resulted in a positive feedback loop, whereby visitors were willing to increasingly trade-off access in order to achieve soundscape and biodiversity conservation.

Though we did not demonstrate a reduction in bird space use near the roadway in response to reductions in speed limits and background sound levels, reducing speed limits should not be abandoned as a potential soundscape mitigation strategy, especially as this approach resulted in increased positive experiences for park visitors. As mentioned, there were limitations to this study which occurred in a single study area and over one season. If managers could change speed limits at multiple sites and couple quieting efforts with other conservation objectives, this would provide an excellent adaptive management opportunity (Williams 2011).

A large body of research has found that noise has negative effects on both people and wildlife (Shannon et al. 2016, Francis et al. 2017). No one-size-fits-all approach exists for addressing the complex issues of roads and traffic noise. Varied and iterative mitigation approaches will allow managers of protected areas to find a balance between undue effects on wildlife and visitor experience and visitor acceptability of these strategies. Finding ways to quiet roadways is of utmost importance. Our work suggests that doing so only increases the cry for the conservation of natural soundscapes.

Responses to this article can be read online at: https://www.ecologyandsociety.org/issues/responses. $\mathrm{php} / 12277$

\section{Acknowledgments:}

We thank Jenn Newton and the entire Grand Teton National Park staff and rangers for access to study areas and mitigation logistics, the NPS Natural Sounds and Night Skies division for use of equipment and technical support, $R$. Barber and $H$. Cole for project set-up and maintenance, and the National Science Foundation (CNH 1414171) for project funding. We also thank the University 
of Wyoming National Park Service Research Center for a grant covering field housing costs during data collection at Grand Teton National Park.

\section{Data Availability:}

The datalcode that support the findings of this study are available for review on Dryad: https://datadryad.org/stash/sharel FzU0q4H2NUTb2miY3eJJaewkOb4 iyTVdCcKtfV1Nl8

\section{LITERATURE CITED}

Alldredge, M. W., T. R. Simons, and K. H. Pollock. 2007. Factors affecting aural detections of songbirds. Ecological Applications 17(3):948-955. https://doi.org/10.1890/06-0685

Ament, R., A. P. Clevenger, O. Yu, and A. Hardy. 2008. An assessment of road impacts on wildlife populations in U.S. national parks. Environmental Management 42(3):480-496. https://doi.org/10.1007/s00267-008-9112-8

Arnold, T. W. 2010. Uninformative parameters and model selection using Akaike's information criterion. Journal of Wildlife Management 74(6):1175-1178. https://doi.org/10.2193/2009-367

Ballantyne, R., J. Packer, and K. Hughes. 2009. Tourists' support for conservation messages and sustainable management practices in wildlife tourism experiences. Tourism Management 30 (5):658-664. https://doi.org/10.1016/j.tourman.2008.11.003

Barber, J. R., C. L. Burdett, S. E. Reed, K. A. Warner, C. Formichella, K. R. Crooks, D. M. Theobald, and K. M. Fristrup. 2011. Anthropogenic noise exposure in protected natural areas: estimating the scale of ecological consequences. Landscape Ecology 26(9):1281-1295. https://doi.org/10.1007/s10980-011-9646-7

Barber, J. R., K. R. Crooks, and K. M. Fristrup. 2010. The costs of chronic noise exposure for terrestrial organisms. Trends in Ecology and Evolution 25(3):180-189. https://doi.org/10.1016/j. tree.2009.08.002

Bartoń, K. 2016. MuMIn: multi-model inference.

Bates, D., M. Machler, B. Bolker, and S. Walker. 2015. Fitting linear mixed-effects models using lme4. Journal of Statistical Software 67(1):1-48. https://doi.org/10.18637/jss.v067.i01

Bee, M. A., and E. M. Swanson. 2007. Auditory masking of anuran advertisement calls by road traffic noise. Animal Behaviour 74(6):1765-1776. https://doi.org/10.1016/j.anbehav.2007.03.019

Belaire, J. A., L. M. Westphal, C. J. Whelan, and E. S. Minor. 2015. Urban residents' perceptions of birds in the neighborhood: biodiversity, cultural ecosystem services, and disservices. Condor 117(2):192-202. https://doi.org/10.1650/condor-14-128.1

Benfield, J. A., G. A. Nurse, A. W. Gibson, B. D. Taff, P. Newman, and P. A. Bell. 2014. Testing noise in the field: a brief measure of individual noise sensitivity. Environment and Behavior 46 (3):353-372. https://doi.org/10.1177/0013916512454430

Benfield, J., B. D. Taff, D. Weinzimmer, and P. Newman. 2018. Motorized recreation sounds influence nature scene evaluations: the role of attitude moderators. Frontiers in Psychology 9:495. https://doi.org/10.3389/fpsyg.2018.00495
Bruce, N. S., and W. J. Davies. 2014. The effects of expectation on the perception of soundscapes. Applied Acoustics 85:1-11. https:// doi.org/10.1016/j.apacoust.2014.03.016

Bunkley, J. P., and J. R. Barber. 2015. Noise reduces foraging efficiency in pallid bats (Antrozous pallidus). Ethology 121 (11):1116-1121. https://doi.org/10.1111/eth.12428

Burnham, K. P., and D. R. Anderson. 2002. Model selection and multimodel inference: a practical information-theoretic approach. Second edition. Springer, New York, New York, USA.

Buxton, R. T., M. F. McKenna, D. Mennitt, K. Fristrup, K. Crooks, L. Angeloni, and G. Wittemyer. 2017. Noise pollution is pervasive in U.S. protected areas. Science 356(6337):531-533. https://doi.org/10.1126/science.aah4783

Cahill, K. L., J. L. Marion, and S. R. Lawson. 2008. Exploring visitor acceptability for hardening trails to sustain visitation and minimise impacts. Journal of Sustainable Tourism 16(2):232-245. https://doi.org/10.2167/jost804.0

Coffin, A. W. 2007. From roadkill to road ecology: a review of the ecological effects of roads. Journal of Transport Geography 15 (5):396-406. https://doi.org/10.1016/j.jtrangeo.2006.11.006

Davies, W. J., M. D. Adams, N. S. Bruce, M. Marselle, R. Cain, P. Jennings, J. Poxon, A. Carlyle, P. Cusack, D. A. Hall, A. Irwin, K. I. Hulme, and C. J. Plack. 2009. The positive soundscape project: a synthesis of results from many disciplines. Pages 663-672 in 38th International Congress and Exposition on Noise Control Engineering 2009 (INTER-NOISE 2009). Noise Control Foundation, Ohio, USA. [online] URL: https://usir.salford.ac.uk/ id/eprint/2106

Dominoni, D. M., W. Halfwerk, E. Baird, R. T. Buxton, E. Fernández-Juricic, K. M. Fristrup, M. F. McKenna, D. J. Mennitt, E. K. Perkin, B. M. Seymoure, D. C. Stoner, J. B. Tennessen, C. A. Toth, L. P. Tyrrell, A. Wilson, C. D. Francis, N. H. Carter, and J. R. Barber. 2020. Why conservation biology can benefit from sensory ecology. Nature Ecology and Evolution 4 (4):502-511. https://doi.org/10.1038/s41559-020-1135-4

Dulac, J. 2013. Global land transport infrastructure requirements. International Energy Agency, Paris, France. [online] URL: https://doi.org/10.1.1.378.8623

Fahrig, L., and T. Rytwinski. 2009. Effects of roads on animal abundance: an empirical review and synthesis. Ecology and Society 14(1):21-41. https://doi.org/10.5751/ES-02815-140121

Francis, C. D., and J. R. Barber. 2013. A framework for understanding noise impacts on wildlife: an urgent conservation priority. Frontiers in Ecology and the Environment 11(6):305-313. https://doi.org/10.1890/120183

Francis, C. D., P. Newman, B. D. Taff, C. White, C. A. Monz, M. Levenhagen, A. R. Petrelli, L. C. Abbott, J. Newton, S. Burson, C. B. Cooper, K. M. Fristrup, C. J. W. McClure, D. Mennitt, M. Giamellaro, and J. R. Barber. 2017. Acoustic environments matter: synergistic benefits to humans and ecological communities. Journal of Environmental Management 203:245-254. https://doi.org/10.1016/j.jenvman.2017.07.041

Gentry, K. E., and D. A. Luther. 2017. Spatiotemporal patterns of avian vocal activity in relation to urban and rural background 
noise. Journal of Ecoacoustics1:\#Z9TQHU. https://doi. org/10.22261/jea.z9tqhu

Guillén, J., and I. López Barrio. 2007. Importance of personal, attitudinal and contextual variables in the assesment of pleasantness of the urban sound environment.19th International Congress on Acoustics, Madrid, Spain.https://hdl.handle. net/10261/5296

Gurule-Small, G. A., and R. M. Tinghitella. 2018. Developmental experience with anthropogenic noise hinders adult mate location in an acoustically signalling invertebrate. Biology Letters 14 (2):20170714. https://doi.org/10.1098/rsbl.2017.0714

Halfwerk, W., L. J. M. Holleman, C. M. Lessells, and H. Slabbekoorn. 2011. Negative impact of traffic noise on avian reproductive success. Journal of Applied Ecology 48:210-219. https://doi.org/10.1111/j.1365-2664.2010.01914.x

Hanni, D., C. M. White, J. A. Blakesly, G. J. Levandoski, and J. J. Birek. 2009. Point transect protocol. Unpublished report. Rocky Mountain Bird Observatory, Brighton, Colorado, USA. [online] URL: http://www.rmbo.org-point transect protocol-2009.pdf

Holmes, T. P., W. L. Adamowicz, and F. Carlsson. 2017. Choice experiments. Pages 133-186 in P.A. Champ, K. Boyle, and T. C. Brown, editors. A primer on nonmarket valuation: the economics of non-market goods and resources. Springer, Dordrecht, Netherlands. http://dx.doi.org/10.1007/978-94-007-7104-8 5

Ibisch, P. L., M. T. Hoffmann, S. Kreft, G. Pe'er, V. Kat, L. BiberFreudenberger, D. A. DellaSala, M. M. Vale, P. R. Hobson, and N. Selva. 2016. A global map of roadless areas and their conservation status. Science 354(6318):1423-1427. https://doi. org/10.1126/science.aaf7166

Kight, C. R., and J. P. Swaddle. 2011. How and why environmental noise impacts animals: an integrative, mechanistic review. Ecology Letters 14(10):1052-1061. https://doi.org/10.1111/j.1461-0248.2011.01664. $\underline{\mathrm{x}}$

Kight, C. R., M. S. Saha, and J. P. Swaddle. 2012. Anthropogenic noise is associated with reductions in the productivity of breeding Eastern Bluebirds (Sialia sialis). Ecological Applications 22 (7):1989-1996. https://doi.org/10.1890/12-0133.1

Kleist, N. J., R. P. Guralnick, A. Cruz, C. A. Lowry, and C. D. Francis. 2018. Chronic anthropogenic noise disrupts glucocorticoid signaling and has multiple effects on fitness in an avian community. Proceedings of the National Academy of Sciences 115(4):E648-E657. https://doi.org/10.1073/pnas.1709200115

Laurance, W. F., G. R. Clements, S. Sloan, C. S. O’Connell, N. D. Mueller, M. Goosem, O. Venter, D. P. Edwards, B. Phalan, A. Balmford, R. Van Der Ree, and I. B. Arrea. 2014. A global strategy for road building. Nature 513(7517):229-232. https://doi. org/10.1038/nature13717

Lawson, S. R., and R. E. Manning. 2002. Tradeoffs among social, resource, and management attributes of the Denali wilderness experience: a contextual approach to normative research. Leisure Sciences 24(3-4):297-312. https://doi.org/10.1080/01490400290050754

Lawson, S. R., and R. E. Manning. 2003. Research to guide management of backcountry camping at Isle Royale National
Park: part II-prescriptive research. Journal of Park and Recreation Administration 21(3):43-57. [online] URL: https://js. sagamorepub. com/jpra/article/view/1498

Lee, N., J. L. Ward, A. Vélez, C. Micheyl, and M. A. Bee. 2017. Frogs exploit statistical regularities in noisy acoustic scenes to solve cocktail-party-like-problems. Current Biology 27(5):1-8. https://doi.org/10.1016/j.cub.2017.01.031

Lynch, E., D. Joyce, and K. Fristrup. 2011. An assessment of noise audibility and sound levels in U.S. national parks. Landscape Ecology 26(9):1297-1309. https://doi.org/10.1007/s10980-011-9643$\underline{\mathrm{X}}$

Madadi, H., H. Moradi, A. Soffianian, A. Salmanmahiny, J. Senn, and D. Geneletti. 2017. Degradation of natural habitats by roads: comparing land-take and noise effect zone. Environmental Impact Assessment Review 65:147-155. https://doi.org/10.1016/j.eiar.2017.05.003

Manning, R. 2011. Studies in outdoor recreation: search and research for satisfaction. Oregon State University Press, Corvallis, Oregon, USA.

Marin, L. D., P. Newman, R. Manning, J. J. Vaske, and D. Stack. 2011. Motivation and acceptability norms of human-caused sound in Muir Woods National Monument. Leisure Sciences 33 (2):147-161. https://doi.org/10.1080/01490400.2011.550224

McClure, C. J. W., J. R. Barber, H. E. Ware, J. Carlisle, and G. Kaltenecker. 2013. An experimental investigation into the effects of traffic noise on distributions of birds: avoiding the phantom road. Proceedings of the Royal Society of London B: Biological Sciences 280(1773):20132290. https://doi.org/10.1098/rspb.2013.2290

McClure, C. J. W., A. C. Korte, J. A. Heath, and J. R. Barber. 2015. Pavement and riparian forest shape the bird community along an urban river corridor. Global Ecology and Conservation 4:291-310. https://doi.org/10.1016/j.gecco.2015.07.004

McClure, C. J. W., H. E. Ware, J. D. Carlisle, and J. R. Barber. 2017. Noise from a phantom road experiment alters the age structure of a community of migrating birds. Animal Conservation 20(2):164-172. https://doi.org/10.1111/acv.12302

Miller, D. L. 2016. Distance: distance sampling detection function and abundance estimation. $\mathrm{R}$ package version 0.9.6. [online] URL: https://cran.r-project.org/web/packages/Distance/index.html

Miller, Z. D., B. D. Taff, and P. Newman. 2018. Visitor experiences of wilderness soundscapes in Denali National Park and Preserve. International Journal of Wilderness 24(2):32-43. [online] URL: https://ijw.org/mountaineers-in-denali/

National Park Service. 2017. Annual park recreation visitation (1904-2016): Grand Teton National Park, Wyoming, USA. [online] URL: https://www.nps.gov/aboutus/visitation-numbers. $\underline{\mathrm{htm}}$

National Research Council (US). 2004. Basics of sound, the ear, and hearing. Pages 42-68 in R.A. Dobie and S. Van Hemel, editors Hearing loss: determining eligibility for social security benefits. National Academies Press, Washington, D.C., USA. https://doi. org/10.17226/11099 
Newman, P., R. Manning, D. Dennis, and W. McKonly. 2005. Informing carrying capacity decision making in Yosemite National Park, USA using stated choice modeling. Journal of Park and Recreation Administration 23(1):75-89. [online] URL: https://js.sagamorepub.com/jpra/issue/view/183

Ortega, C. P., and C. D. Francis. 2012. Effects of gas-wellcompressor noise on the ability to detect birds during surveys in northwest New Mexico. Ornithological Monographs 74(1):78-90. https://doi.org/10.1525/om.2012.74.1.78

Pacifici, J. K., T. R. Simons, and K. H. Pollock. 2008. Effects of vegetation and background noise on the detection process in auditory avian point-count surveys. Auk 125(3):600-607. https:// doi.org/10.1525/auk.2008.07078

Parris, K. M., and A. Schneider. 2008. Impacts of traffic noise and traffic volume on birds of roadside habitats. Ecology and Society 14(1):19. https://doi.org/10.5751/ES-02761-140129

Peel, K.A. 2000. National Park Service director's order \#47: soundscape preservation and noise management. [online] URL: https://www.nps.gov/policy/DOrders/DOrder47.html

Pilcher, E. J., P. Newman, and R. E. Manning. 2009. Understanding and managing experiential aspects of soundscapes at Muir Woods National Monument. Environmental Management 43(3):425-435. https://doi.org/10.1007/s00267-008-9224-1

Proppe, D. S., and E. Finch. 2017. Vocalizing during gaps in anthropogenic noise is an uncommon trait for enhancing communication in songbirds. Journal of Ecoacoustics 1(1), 3. $\underline{10.22261 / j e a . t . p 6 d}$

R Core Team. 2016. R: a language and environment for statistical computing. R Foundation for Statistical Computing, Vienna, Austria. [online] URL: https://www.gbif.org/tool/81287/r-alanguage-and-environment-for-statistical-computing

Reijnen, R., and R. Foppen. 2006. Impact of road traffic on breeding bird populations. Pages 255-274 in J. Davenport and J. L. Davenport, editors. The ecology of transportation: managing mobility for the environment. Springer, Dordrecht, The Netherlands. https://doi.org/10.1007/1-4020-4504-2 12

Revelt, D., and K. Train. 2000. Customer-specific taste parameters and mixed logit: households' choice of electricity supplier. Econometrics 0012001. University of Munich, Germany. [online] URL: RePEc:wpa:wuwpem:0012001

Sauer, J. R., B. G. Peterjohn, and W. A. Link. 1994. Observer differences in the North American breeding bird survey. Auk 111 (1):50-62. https://doi.org/10.2307/4088504

Shannon, G., L. M. Angeloni, G. Wittemyer, K. M. Fristrup, and K. R. Crooks. 2014. Road traffic noise modifies behaviour of a keystone species. Animal Behaviour 94:135-141. https://doi. org/10.1016/j.anbehav.2014.06.004

Shannon, G., M. F. McKenna, L. M. Angeloni, K. R. Crooks, K. M. Fristrup, E. Brown, K. A. Warner, M. D. Nelson, C. White, J. Briggs, S. McFarland, and G. Wittemyer. 2016. A synthesis of two decades of research documenting the effects of noise on wildlife. Biological Reviews 91(4):982-1005. https://doi. org/10.1111/brv. 12207
Siemers, B. M., and A. Schaub. 2010. Hunting at the highway: traffic noise reduces foraging efficiency in acoustic predators. Proceedings of the Royal Society B: Biological Sciences 278 (1712):1646-1652. https://doi.org/10.1098/rspb.2010.2262

Simons, T. R., M. W. Alldredge, K. H. Pollock, and J. M. Wettroth. 2007. Experimental analysis of the auditory detection process on avian point counts. Auk 124(3):986-999. https://doi.org/10.1093/ $\underline{\text { auk/124.3.986 }}$

Venables, W. N., and B. D. Ripley. 2002. Modern applied statistics with $S$. Fourth edition. Springer, New York, New York, USA.

Ware, H. E., C. J. W. McClure, J. D. Carlisle, and J. R. Barber. 2015. A phantom road experiment reveals traffic noise is an invisible source of habitat degradation. Proceedings of the National Academy of Sciences 112(39):12105-12109. https://doi. org/10.1073/pnas. 1504710112

Weinzimmer, D., P. Newman, D. Taff, J. Benfield, E. Lynch, and P. Bell. 2014. Human responses to simulated motorized noise in national parks. Leisure Sciences 36(3):251-267. https://doi. org/10.1080/01490400.2014.888022

Williams, B. K. 2011. Adaptive management of natural resources - framework and issues. Journal of Environmental Management 92(5):1346-1353. https://doi.org/10.1016/j.jenvman.2010.10.041 


\section{Supplementary Materials}

\section{Bird count detectability}

Detectability can vary with multiple observers (Sauer et al. 1994, Alldredge et al. 2007, McClure et al. 2015) and in relation to excessive background noise (Simons et al. 2007, Pacifici et al. 2008, McClure et al. 2015). To combat the effects of multiple observer bias, our study used a single point count observer. Though our average L50 sound levels were below and just above 45 $\mathrm{dB}(\mathrm{A})$, the approximate threshold beyond which impairs human ability to detect birds (Ortega and Francis 2012), we examined potential differences in the probability of bird detection between sign absent and sign present treatment blocks using package Distance (Miller 2016) in Program R. We built several models using the different key functions and modeling detection either as intercept-only or as a function of treatment. We then ranked and compared detection models using Akaike's information criterion (AIC) (Arnold 2010). We considered there to be an effect of treatment on detection if the factor for treatment was in a model within the top $98 \%$ of cumulative model weight (Burnham and Anderson 2003) and was not an uninformative parameter (Arnold 2010). Although a treatment model was indeed within $98 \%$ of the cumulative model weight, it was an uninformative parameter because the parameters in the AIC-best model were a subset of those in the treatment model and the $95 \%$ (and $85 \%$ ) confidence intervals on the treatment coefficient overlapped zero (Arnold 2010). We therefore concluded there were no differences in detectability between treatment blocks and did not adjust observation counts (Table S5). 


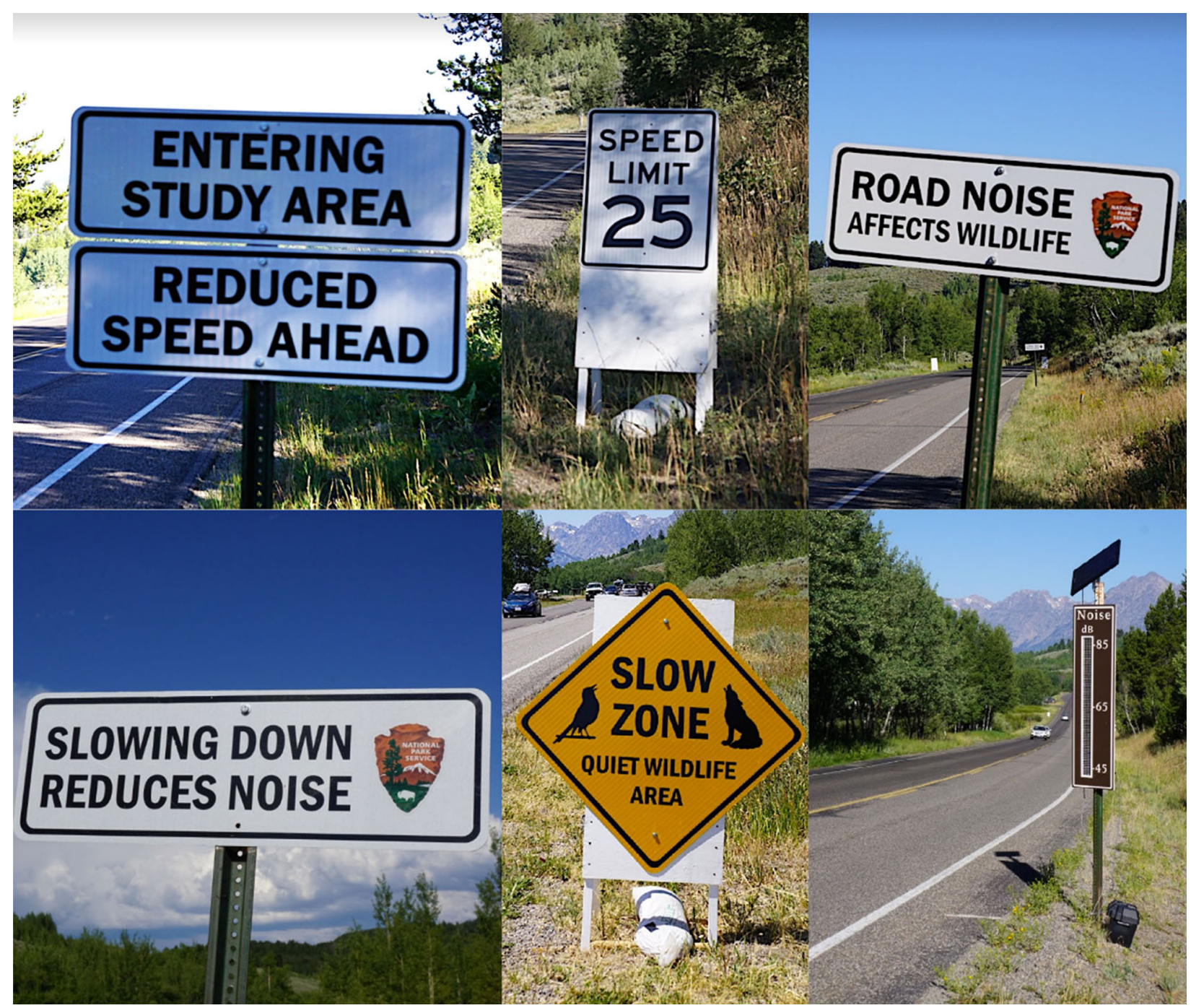

Fig. S1. Enforcement and educational signage used within the experimental road corridor during treatment blocks.

Table S1. Speed limit counts classified by traffic counter.

\begin{tabular}{lcc}
\hline \hline Speed (mph) & Signs Absent (n) & Signs Present (n) \\
\hline $5-14 \mathrm{mph}$ & 90 & 154 \\
$15-19 \mathrm{mph}$ & 68 & 547 \\
$20-24 \mathrm{mph}$ & 125 & 5,145 \\
$25-29 \mathrm{mph}$ & 433 & 17,871 \\
$30-34 \mathrm{mph}$ & 1,395 & 20,447 \\
$35-39 \mathrm{mph}$ & 5,956 & 21,564 \\
$40-44 \mathrm{mph}$ & 22,944 & 20,899 \\
$45-49 \mathrm{mph}$ & 46,199 & 14,897 \\
$50-54 \mathrm{mph}$ & 27,785 & 5,589 \\
$55-59 \mathrm{mph}$ & 7,796 & 1,469
\end{tabular}




\begin{tabular}{lcc}
$60-64 \mathrm{mph}$ & 1,558 & 343 \\
$65-69 \mathrm{mph}$ & 303 & 77 \\
$70-74 \mathrm{mph}$ & 87 & 37 \\
$75-79 \mathrm{mph}$ & 24 & 17 \\
$80-99 \mathrm{mph}$ & 56 & 34 \\
\hline Total & 114,819 & 109,090 \\
\hline
\end{tabular}

Table S2. Results of Kruskal-Wallis statistical test for driving speed between treatment blocks.

\begin{tabular}{lcccc}
\hline \hline Speed $(\mathrm{mph})$ & $\mathrm{n}$ & Kruskal-Wallis chi-squared & $\mathrm{df}$ & $\mathrm{p}$ \\
\hline $5-24 \mathrm{mph}$ & 6,129 & 51.62 & 1 & $<0.001$ \\
$25-49 \mathrm{mph}$ & 172,605 & 6.90 & 1 & 0.009 \\
$50-74 \mathrm{mph}$ & 45,044 & 37.73 & 1 & $<0.001$ \\
$75+\mathrm{mph}$ & 131 & 0.17 & 1 & 0.68 \\
\hline
\end{tabular}

Table S3. Species detected during bird survey counts ( $<50 \mathrm{~m}$ from point count center).

\begin{tabular}{lcc}
\hline \hline Common Name & Scientific Name & Count (\#) \\
\hline Yellow Warbler & Setophaga petechia & 317 \\
White-crowned Sparrow & Zonotrichia leucophrys & 159 \\
Warbling Vireo & Vireo gilvus & 123 \\
Dusky Flycatcher & Empidonax oberholseri & 116 \\
Green-tailed Towhee & Pipilo chlorurus & 62 \\
Tree Swallow & Tachycineta bicolor & 61 \\
Pine Siskin & Spinus pinus & 57 \\
Song Sparrow & Melospiza melodia & 55 \\
Lazuli Bunting & Passerina amoena & 41 \\
Lincoln's Sparrow & Melospiza lincolnii & 41 \\
American Robin & Turdus migratorius & 37 \\
Chipping Sparrow & Spizella passerina & 34 \\
Common Yellowthroat & Geothlypis trichas & 33 \\
Audubon's Warbler & Setophaga coronata auduboni & 32 \\
Cedar Waxwing & Bombycilla cedrorum & 28 \\
Willow Flycatcher & Empidonax traillii & 23 \\
Gray Catbird & Dumetella carolinensis & 20 \\
House Wren & Troglodytes aedon & 19 \\
Fox Sparrow & Passerella iliaca & 17 \\
Red-naped Sapsucker & Sphyrapicus nuchalis & 16 \\
Western Tanager & Piranga ludoviciana & 15 \\
Mountain Chickadee & Poecile gambeli & 14 \\
Brewer's Blackbird & Euphagus cyanocephalus & 12 \\
Calliope Hummingbird & Selasphorus calliope & 10 \\
Dark-eyed Junco & Junco hyemalis & 10 \\
Clark's Nutcracker & Nucifraga columbiana & 6 \\
Northern Flicker & Colaptes auratus & 6
\end{tabular}




\begin{tabular}{lcc} 
MacGillivray's Warbler & Geothlypis tolmiei & 5 \\
American Goldfinch & Spinus tristis & 4 \\
Brown-headed Cowbird & Molothrus ater & 4 \\
Black-headed Grosbeak & Pheucticus melanocephalus & 3 \\
Broad-tailed Hummingbird & Selasphorus platycercus & 3 \\
Rufous Hummingbird & Selasphorus rufus & 3 \\
American White Pelican & Pelecanus erythrorhynchos & 2 \\
Brewer's Sparrow & Spizella breweri & 2 \\
Common Raven & Corvus corax & 2 \\
Downy Woodpecker & Dryobates pubescens & 2 \\
Hairy Woodpecker & Dryobates villosus & 2 \\
Swainson's Thrush & Catharus ustulatus & 2 \\
Bullock's Oriole & Icterus bullockii & 1 \\
Mountain Bluebird & Sialia currucoides & 1 \\
Red-tailed Hawk & Buteo jamaicensis & 1 \\
Townsend's Warbler & Setophaga townsendi & 1 \\
\hline Total & & 1,402 \\
\hline
\end{tabular}

Table S4. Generalized linear mixed model results for all species combined and for individual bird species with $>100$ observations. Models include daily-averaged L50 and Julian Date as scaled fixed effects and a random effect for site. The conditional variance $\left(\mathrm{R}^{2}{ }_{\text {GLMM(c) }}\right)$ is the variance explained by both fixed and random effects. $* p<.05, * * * p<.001$

\begin{tabular}{|c|c|c|c|c|c|c|c|}
\hline Scientific Name & $\mathrm{n}$ & & Intercept & $\begin{array}{c}\text { Daily- } \\
\text { averaged L50 } \\
(\mathrm{dB}(\mathrm{A})) \\
\text { (scaled) }\end{array}$ & $\begin{array}{c}\text { Julian } \\
\text { Date } \\
\text { (scaled) }\end{array}$ & $\begin{array}{c}\text { Variance } \\
\text { (Random } \\
\text { Effect) }\end{array}$ & $\mathrm{R}_{\mathrm{GLMM}(\mathrm{c})}$ \\
\hline \multirow[t]{3}{*}{ All Species } & 212 & $\beta$ & 1.86 & -0.05 & -0.21 & 0.09 & 0.45 \\
\hline & & S.E. & 0.10 & 0.06 & 0.03 & & \\
\hline & & $\mathrm{p}$ & $<0.001 * * *$ & 0.32 & $<0.001 * * *$ & & \\
\hline \multirow[t]{3}{*}{ Setophaga petechia } & 212 & $\beta$ & -0.77 & -0.04 & -0.32 & 4.21 & 0.79 \\
\hline & & S.E. & 0.65 & 0.14 & 0.06 & & \\
\hline & & $\mathrm{p}$ & 0.23 & 0.80 & $<0.001 * * *$ & & \\
\hline \multirow[t]{3}{*}{ Zonotrichia leucophrys } & 212 & $\beta$ & -0.45 & -0.08 & -0.07 & 0.34 & 0.27 \\
\hline & & S.E. & 0.20 & 0.14 & 0.08 & & \\
\hline & & $\mathrm{p}$ & $0.02 *$ & 0.58 & 0.40 & & \\
\hline \multirow[t]{3}{*}{ Empidonax oberholseri } & 212 & $\beta$ & -0.81 & -0.02 & -0.21 & 0.37 & 0.26 \\
\hline & & S.E. & 0.22 & 0.16 & 0.10 & & \\
\hline & & $\mathrm{p}$ & $<0.001 * * *$ & 0.88 & $0.03 *$ & & \\
\hline
\end{tabular}


Vireo gilvus

212

$\begin{array}{cc}\beta & -0.84 \\ \text { S.E. } & 0.22 \\ \mathrm{p} & <0.001 * * *\end{array}$

$-0.09$

$-0.45$

0.34

0.31

0.18

0.10

0.59

$<0.001 * * *$

Table S5. AIC table for bird detectability models.

\begin{tabular}{lccccc}
\hline \hline Model Key Function & Formula & AIC & $\boldsymbol{\Delta A I C}$ & $\begin{array}{c}\text { Relative Likelihood } \\
\left(\exp \left(-0.5^{*} \boldsymbol{\Delta A I C}\right)\right)\end{array}$ & wi \\
\hline $\begin{array}{l}\text { Uniform with cosine adjustment } \\
\text { terms of order 1,2,3 }\end{array}$ & NA & 10108.01 & 0.00 & 1.00 & 0.30 \\
Uniform with cosine adjustment & NA & 10108.74 & 0.73 & 0.69 & 0.21 \\
terms of order 1,2 & $\sim 1$ & 10108.94 & 0.94 & 0.63 & 0.19 \\
Hazard-rate & $\sim 1$ & 10110.23 & 2.22 & 0.33 & 0.10 \\
Half-normal with cosine & $\sim 1$ & 10110.64 & 2.63 & 0.27 & 0.08 \\
adjustment term of order 2 & $\sim$ Treatment & 10110.68 & 2.67 & 0.26 & 0.08 \\
Half-normal & $\sim$ Treatment & 10112.53 & 4.53 & 0.10 & 0.03 \\
Hazard-rate & & & & 3.28 & \\
Half-normal & & & &
\end{tabular}

